Перспективность использования ультрадисперсной формы металлов в кормлении животных

\author{
Е.А. Сизова ${ }^{1,2}$, К.С. Нечитайло ${ }^{1}$, А.П. Иванищева ${ }^{1}$ Н.И. Рябов ${ }^{1}$ \\ ${ }^{1}$ Федеральньй научный центр биологических систем и агротехнологий Российской академии наук (2. Оренбург) \\ ${ }^{2}$ Оренбургский государственный университет (2. Оренбург)
}

\begin{abstract}
Аннотация. Перспективы использования ультрадисперсных металлических форм в значительной степени определяются их биологическими свойствами и способностью выступать в качестве источников микроэлементов в питании животных. Обладая заявленными характеристиками, они могут составить конкуренцию неорганическим формам, входящим в состав премиксов. Цель исследований состояла в изучении эффективности ультрадисперсной формы меди и цинка как минеральной кормовой добавки в рационе птицы в сравнении с неорганической и органической формами этих элементов. Применение указанного подхода приводит к положительному продуктивному эффекту. Ультрадисперсная форма металлов повышает активность аминотрансфераз, что является как критерием интенсивности реакции переаминирования аминокислот, так и маркером целостности клеток. При этом гистологическая картина печени опытных групп сходна с контрольной. В то же время отсутствие окислительного стресса подтверждает динамика активности показателей антиоксидантной системы крови, концентрация которых не превышала контрольные значения. Замена в рационе цыплят-бройлеров сульфатов меди и цинка на ультрадисперсную их форму (I группа) и органическую форму (II группа) сопровождалась увеличением пула этих элементов в организме цыплят-бройлеров в конце эксперимента. Обнаружена зависимость накопления элемента от формы вводимого металла. Медь накапливается в течение всего эксперимента со статистически значимой разницей в печени и пере в I опытной группе. Концентрации меди при введении её органической формы близки к контролю. Динамика концентрации цинка в пере имеет общую тенденцию снижения с возрастом во всех группах. Использование ультрадисперсной формы приводит к возрастанию концентрации цинка в печени к концу эксперимента. Таким образом, ультрадисперсный сплав может стать альтернативой неорганической и органической формам изучаемых элементов в питании птицы.
\end{abstract}

Ключевые слова: цыплята-бройлеры, кормление, цинк, медь, ультрадисперсная форма, микроэлементы, биохимические показатели, элементный состав, печень, перо.

UDC 636.085:577.17

\title{
The prospects of using ultra-dispersed forms of metals in animal feeding
}

\author{
Elena A Sizoval, ${ }^{1,2}$ Kseniya S Nechitailo ${ }^{1}$, Anastasia P Ivanischeva ${ }^{1}$, Nikolay I Ryabov ${ }^{1}$ \\ ${ }^{I}$ Federal Research Centre of Biological Systems and Agrotechnologies of the Russian Academy of Sciences (Orenburg, Russia) \\ ${ }^{2}$ Orenburg State University (Orenburg, Russia)
}

Summary. The unique prospects of using ultrafine metal forms are largely determined by their rare biological properties and their ability to act as sources of trace elements in animal nutrition. Possessing the declared characteristics, they can compete with the inorganic forms that are part of premixes for farm animals. The aim of the study was to study the effectiveness of the ultrafine alloy of copper and zinc as a dispersed inorganic material in poultry feeding in comparison with the inorganic and organic forms of these elements. The application of this approach leads to a positive productive effect. The ultrafine form of metals increases the activity of aminotransferases, which is a criterion for characterizing the level of the involvement of amino acid parts in biochemical processes due to reverse transfer reactions. It is also an indicator of changes in the passage of cell membranes of internal organs. Moreover, the histological 
picture of the liver of the experimental groups is similar to the control. At the same time, the absence of oxidative stress confirms the dynamics of the activity of indicators of the antioxidant system of the blood, the concentrations of which did not exceed the control values. The replacement of copper and zinc sulfates in the diet of broiler chickens with an ultrafine alloy of these elements (group I) and organic form (group II) was accompanied by an increase in the pool of these elements in broiler chickens at the end of the experiment. In the experiment, the dependence of the accumulation of the element on the form of the introduced metal was found. Copper accumulates throughout the experiment with a statistically significant difference in the liver and feather in the experimental group I. The concentration of copper with the introduction of its organic form is close to control. The dynamics of zinc concentration in feathers has a general tendency to decrease with age in all groups. The use of an ultrafine alloy leads to an increase in the concentration of zinc in the liver by the end of the experiment. Thus, the ultrafine form can become an alternative to the inorganic and organic forms of the studied elements in the nutrition of poultry.

Key words: broiler chickens, feeding, zinc, copper, ultrafine form, trace elements, biochemical parameters, elemental composition, liver, feather.

\section{Введение.}

Основной целью применения ультрадисперсных форм микроэлементов в сельском хозяйстве является их использование в качестве минеральной кормовой добавки. Это определяется относительно меньшей токсичностью ультрадисперсных форм (УДФ) металлов-микроэлементов (Mishra B et al., 2010; Zhang H et al., 2011), высокой биодоступностью (Scott A et al., 2018). Обладая заявленными характеристиками, УДФ могут составить конкуренцию существующим минеральным веществам, входящим в состав премиксов для сельскохозяйственных животных. К тому же высокая эффективность УДФ металлов по сравнению с неорганическими солями и другими источниками подтверждается рядом исследований (Yausheva EV et al., 2015; Mroczek-Sosnowska N et al., 2016; Ognik K et al., 2018).

Апробированным в мировой науке является использование в животноводстве различных ультрадисперсных источников микроэлементов (Mohammadi V et al., 2015; Ognik K et al., 2016; Shirsat S et al., 2016; Siddiqi KS et al., 2016; Hajializadeh F et al., 2017; Farag Mr et al., 2018). В свою очередь, новые технологии синтеза приводят к возможности совместного скармливания микроэлементов-антагонистов (Miroshnikova EP et al., 2015; Сизова Е.А. и др., 2018), что в случае использования неорганических форм не эффективно в виду антагонистических взаимоотношений. Антагонизм между элементами снижает усвояемость отдельных из них, приводит к увеличению дозы введения, что экологически и экономически нецелесообразно. В этой связи перспективными являются разработки альтернативных форм микроэлементов, исключающих антагонистические взаимоотношения на этапе всасывания и обладающих высокой биодоступностью.

В статье впервые показано биологическое и продуктивное действие в отношении цыплятбройлеров разных форм (ультрадисперсной, органической и неорганической) двух эссенциальных микроэлементов - цинка и меди.

\section{Цель исследования.}

Изучение эффективности ультрадисперсных форм меди и цинка как минеральной добавки в кормлении птицы в сравнении с неорганической и органической формами этих элементов.

\section{Материалы и методы исследования.}

Объект исследования. Цыплята-бройлеры кросса «Арбор Айкрес».

Обслуживание животных и экспериментальные исследования были выполнены в соответствии с инструкциями Russian Regulations, 1987 (Order No. 755 on 12.08.1997 the USSR Ministry of Health) и «The Guide for Care and Use of Laboratory Animals (National Academy Press Washington, D.C. 1996)». При выполнении исследований были приняты усилия, чтобы свести к минимуму страдания животных и уменьшения количества используемых образцов. 
Все экспериментальные методы и методики были одобрены Комитетом по этике ФГБНУ ФНЦ БСТ РАН (протокол № 3 от 21 марта 2018 г.).

Схема эксперимента. Эксперимент проводился в условиях вивария ФГБНУ ФНЦ БСТ РАН на цыплятах-бройлерах кросса «Арбор Айкрес» и включал подготовительный (7-13 суток) и основной (14-42 суток) периоды. В 7-суточном возрасте были сформированы три группы: контрольная и две опытных $(\mathrm{n}=24)$. Кормление птицы осуществлялось в соответствии с возрастными периодами с полнорационными комбикормами, составленными с учётом рекомендаций (Фисинин В.И., 2009).

При проведении исследований в качестве источников микроэлементов применяли: неорганическую форму $-\mathrm{FeSO}_{4} \times 7 \mathrm{H}_{2} \mathrm{O}, \mathrm{CuSO}_{4} \times 5 \mathrm{H}_{2} \mathrm{O}$, категории «ЧДА» («Ленреактив», Россия); органическиую форму - аспарагинаты $\mathrm{Cu}, \mathrm{Zn}(\mathrm{OOO}$ «В-Мин+», г. Сергиев Посад). Ультрадисперсные частицы сплава меди и цинка (УДЧ CuZn) предоставлены Институтом физики металлов им. М.Н. Михеева (г. Екатеринбург).

Цыплята контрольной группы в течение всего исследования получали основной рацион, в котором медь и цинк нормировали введением их сульфатов. Цыплятам-бройлерам опытных групп в период с 14-х по 42-е сутки $\mathrm{FeSO}_{4} \times 7 \mathrm{H}_{2} \mathrm{O}$ и $\mathrm{CuSO}_{4} \times 5 \mathrm{H}_{2} \mathrm{O}$ заменяли: в I - на сплавУДЧ $\mathrm{CuZn}$, во II опытной на аспарагинаты $\mathrm{Cu}$ и $\mathrm{Zn}$. Подход к выбору дозы обусловлен рекомендациями (Фисинин В.И., 2009) и с учётом сведений о биодоступности элементов из тестируемых форм доза была снижена на 30 \%. Выбор пары антагонистов (медь, цинк) определялся одинаковым механизмом их абсорбции в кишечнике.

Контроль над ростом подопытной птицы производился ежедневно путём индивидуального взвешивания утром до кормления.

Забор крови у птицы проводили в 21-, 28-, 35- и 42-суточном возрасте из подкрыльцовой вены.

Оборудование и технические средства. Лабораторные исследования проводились в Испытательном центре ЦКП (аттестат аккредитации № RA.RU.21ПФ59 от 02.12.15) ФНЦ БСТ РАН.

Морфологические показатели определяли с помощью автоматического гематологического анализатора модель URIT-2900 VetPlus («URIT Medial Electronic Co. Ltd», Китай). Биохимические исследования сыворотки крови проводились на автоматическом анализаторе CS-T240 («DIRUI Industrial Co., Ltd», Китай) с использованием коммерческих наборов для ветеринарии ДиаВетТест (Россия) и Randox Laboratories Limited (United Kingdom).

Элементный состав тела, печени и пера определяли с использованием масс-спектрометра Elan 9000 и атомно-эмиссионного спектрометра Optima 2000V (PerkinElmer, США). Озоление биосубстратов проводили с использованием микроволновой системы разложения Multiwave-3000 («AntonPaаr», Австрия).

Статистическая обработка. Проверку данных выполняли с помощью офисного программного комплекса «Microsoft Office» с применением программы «Excel» («Microsoft», США) с обработкой данных в «Statistica 10.0» («Stat Soft Inc.», США). Представлены средние (M) истандартные ошибки средних ( $\pm \mathrm{SEM})$. Достоверность различий оценивали по t-критерию Стьюдента, статистически значимыми считали различия $\mathrm{P} \leq 0,05$.

\section{Результаты исследования.}

Поедаемость корма, масса тела. Введение в рацион цыплятам-бройлерам ультрадисперсного сплава отражалось на их продуктивности. Так, предубойная живая масса цыплят-бройлеров в 42-суточном возрасте составила $2576 \pm 18,6$ г, что на $3,33(\mathrm{P} \leq 0,05)$ и $3,84 \%(\mathrm{P} \leq 0,01)$ оказалось больше, чем у контрольных и во II опытной группе. Причём контрольная птица на 4,45 \% потребляла комбикорма больше, чем птица II опытной группы за период эксперимента. В тушке птицы I опытной группы на 5,6 \% мышечной ткани было больше, чем у контрольной птицы.

Биохимические показатели сыворотки крови. Оценивая характер изменений каталитической активности аминотрансфераз, можно констатировать, что замена формы минеральной добавки по- 
Животноводство и кормопроизводство 2020 T. 103 № 3/Animal Husbandry and Fodder Production 2020 Vol. 103 Is. 3 180

Теория и практика кормления

вышала их значение с достоверной разницей по аланинаминотрансферазе (АЛТ) в 2,4 раза $(\mathrm{P} \leq 0,05)$ и 2,2 раза $(\mathrm{P} \leq 0,01)$ для II и I опытных групп соответственно в 28 -дневном возрасте. Активность аспартатаминотрансферазы (АСТ) изменялась в сторону повышения к концу выращивания (табл. 1).

Таблица 1. Динамика активности ферментов сыворотки крови цыплят-бройлеров в эксперименте $(M \pm S E M, n=6)$

Table 1. Dynamics of activity of blood serum enzymes in broiler chickens in the experiment $(\mathrm{M} \pm$ SEM, $\mathbf{n}=\mathbf{6})$

\begin{tabular}{|c|c|c|c|c|}
\hline \multirow{2}{*}{ Группа/Group } & \multicolumn{4}{|c|}{ Возраст, сут/Age, day } \\
\hline & 21 & 28 & 35 & 42 \\
\hline \multicolumn{5}{|c|}{ АЛТ, Е/л/ALT, U/l } \\
\hline I опытная/ I experimental & $1,06 \pm 0,06^{*}$ & $2,83 \pm 0,13^{* *}$ & $2,07 \pm 0,18$ & $4,7 \pm 0,289^{* *}$ \\
\hline II опытная/II experimental & $1,88 \pm 0,07^{*}$ & $3,15 \pm 0,427^{*}$ & $2,83 \pm 0,29$ & $2,37 \pm 0,10$ \\
\hline Контроль/Control & $3,35 \pm 0,15$ & $1,30 \pm 0,189$ & $1,97 \pm 0,18$ & $2,83 \pm 0,19$ \\
\hline \multicolumn{5}{|c|}{ АСТ, Е/л / $A S T, U /$} \\
\hline I опытная/ I experimental & $281,0 \pm 10,7$ & $232,7 \pm 9,9$ & $262,1 \pm 13,1$ & $355,5 \pm 9,4^{*}$ \\
\hline II опытная/II experimental & $230,0 \pm 9,8$ & $244,6 \pm 19,1$ & $221,9 \pm 13,7$ & $272,0 \pm 8,7$ \\
\hline Контроль/Control & $257,2 \pm 9,8$ & $225,9 \pm 6,0$ & $241,4 \pm 10,6$ & $299,9 \pm 12,4$ \\
\hline \multicolumn{5}{|c|}{ ЛДГ, Е/л / LDH, U/l } \\
\hline I опытная/ I experimental & $3098,3 \pm 36,5^{*}$ & $2693,3 \pm 121,4$ & $3104,3 \pm 25,0 * *$ & $2008,0 \pm 24,1 * *$ \\
\hline II опытная/II experimental & $3316,3 \pm 200,4$ & $2992,3 \pm 462,3$ & $2852,0 \pm 111,5$ & $2801,3 \pm 11,3^{*}$ \\
\hline Контроль/Control & $3851,0 \pm 54,0$ & $2512,0 \pm 71,1$ & $2444,3 \pm 15,8$ & $3252,0 \pm 33,8$ \\
\hline \multicolumn{5}{|c|}{ ГГТ, Е/л / GGT, U/l } \\
\hline I опытная/ I experimental & $13,33 \pm 0,882 * *$ & $19,67 \pm 1,764$ & $18,67 \pm 0,333^{*}$ & $22,67 \pm 1,480$ \\
\hline II опытная/II experimental & $19,00 \pm 1,155^{*}$ & $17,00 \pm 0,142$ & $22,33 \pm 1,202$ & $21,67 \pm 0,333$ \\
\hline Контроль/Control & $28,50 \pm 1,500$ & $14,67 \pm 0,882$ & $20,00 \pm 1,646$ & $19,33 \pm 1,404$ \\
\hline
\end{tabular}

Примечание: * $-\mathrm{P} \leq 0,05 ; * *-\mathrm{P} \leq 0,01$

Note: ${ }^{*}-\mathrm{P} \leq 0.05 ; * *-\mathrm{P} \leq 0.01$

В экспериментальных группах не выявлена характерная направленность изменений активности гамма-глутамилтрансферазы (ГГТ) и лактатдегидрогеназы (ЛДГ). Достоверное снижение уровня ГГТ отмечено в 21-суточном возрасте на $53,3 \%(\mathrm{P} \leq 0,01)$ и $33,3 \%(\mathrm{P} \leq 0,05)$ для I и II групп соответственно. В 35-суточном возрасте разница сократилась до $6,65 \%(\mathrm{P} \leq 0,05)$ в I группе. Активность ЛДГ в течение эксперимента изменяется волнообразно. К концу эксперимента активность ЛДГ в I и II опытных группах была ниже контрольной группы на 37,2 \% (P $\leq 0,01)$ и $12,8 \%$ (P $\leq 0,05)$ соответственно.

Антиоксидантная активность крови. На отсутствие окислительного стресса указывала динамика активности каталазы (КТ) и общей супероксиддисмутазы (СОД). Мы не обнаружили пиковых значений их концентрации. На фоне введения смеси аспарагината CuZn (II группа) в первые две недели эксперимента активность КТ нарастала на 55,3-122,2 \% (21-28 сутки; Р $\leq 0,05)$ по сравнению с контролем с последующим спадом ниже контрольных образцов на 18-41,7 \% (35-42 сутки). Введение ультрадисперсного сплава вызвало увеличение активности КТ только на 28 сутки, с последующим спадом значения ниже контроля (рис. 1). 


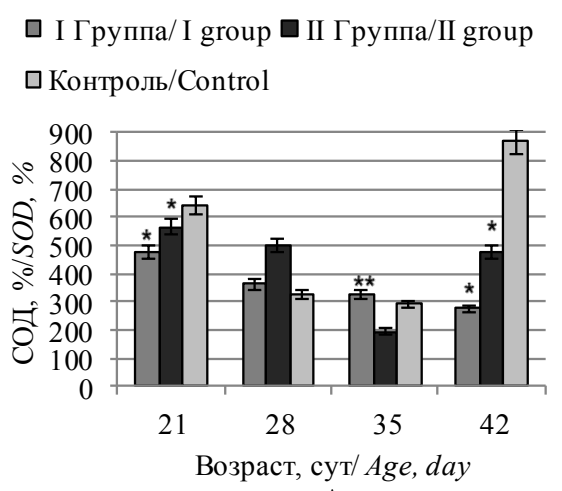

$\mathrm{A}$

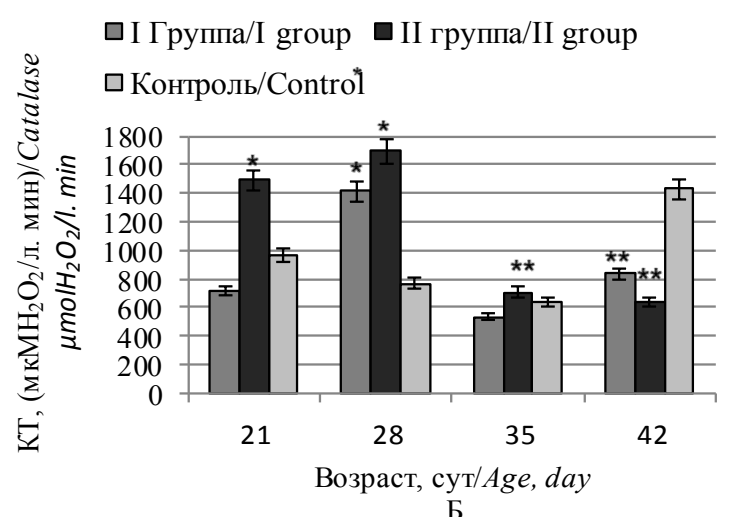

ㄴ Г Группа/Igroup

ч Контроль/Conrol

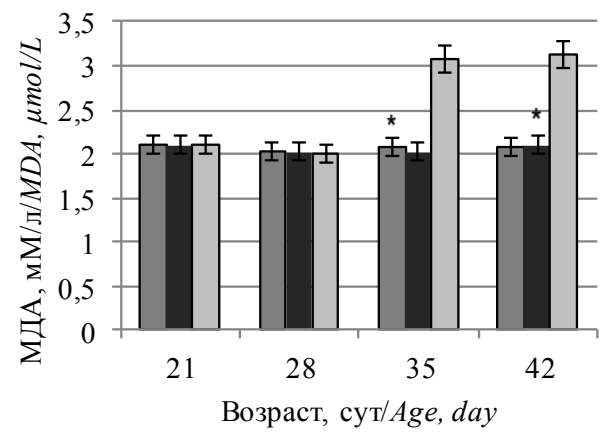

$\mathrm{B}$

II Группа/II group

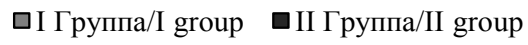

$\square$ Контроль/Control

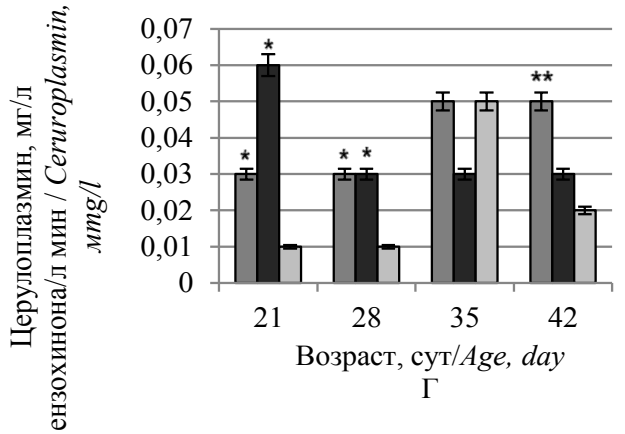

Рис. 1 - Показатели антиоксидантной системы крови цыплят-бройлеров в эксперименте $(M \pm S E M, n=6):$ А - СОД, \%; Б - КТ, мкМН $\mathrm{O}_{2} /$ лмин; В - МДА, мМ/л;

Г - церулоплазмин, мг/л. * - $\mathbf{P} \leq \mathbf{0 . 0 5} ; *$ * $-\mathrm{P} \leq 0.01$

Figure 1 - Indicators of the antioxidant blood system of broiler chickens in the experiment $(\mathrm{M} \pm \mathrm{SEM}, \mathrm{n}=6): \mathrm{A}-\mathrm{T}-\mathrm{SOD}, \%$; $\mathrm{B}-\mathrm{CT}, \mu \mathrm{molH}_{2} \mathrm{O}_{2} / \mathrm{Lmin} ; \mathrm{B}-\mathrm{MDA}, \mu \mathrm{mol} / \mathrm{L}$; $\Gamma$-Ceruloplasmin, mg/L. * $-\mathrm{P} \leq 0.05 ; * *-\mathrm{P} \leq 0.01$

Наряду с СОД и КТ важное место в системе блокировки реакций свободно радикального окисления, восстанавливая разрушенные соединения, занимает церулоплазмин. Его активность в сыворотке крови увеличивается в 1,5-2 раза по сравнению с контролем в 21- и 28-дневном возрасте $(\mathrm{P} \leq 0,05)$.

На фоне использования ультрадисперсногосплава уровень малонового диальдегида (МДА), как коэффициента липопероксидации, в организме цыплят уменьшается к 42-суточному возрасту на $33,3 \%(\mathrm{P} \leq 0,05)$, что говорит о наличии антиоксидантных свойств, при этом отсутствуют факты прооксидантных эффектов используемых препаратов. 
Характеристика микроструктуры печени. В печени контрольной группы выявлено умеренное полнокровие и полиморфноклеточная инфильтрация вокруг междольковых триад при чёткой морфологической организации стромального и паренхиматозного компонентов. В цитоплазме отдельных гепатоцитов наблюдались мелкие вакуоли. В желчных протоках изменений не выявлено.

B I опытной группе структура печени не изменилась. Часто в поле зрения вокруг триад наблюдаются клеточные пролифераты, преимущественно из клеток лимфоидного ряда (рис. 2А). Незначительно расширен просвет центральных вен. Балочная структура долек сохранена. Гепатоциты -с чёткими границами, расположены упорядочено. В цитоплазме отдельных гепатоцитов просматриваются мелкие вакуоли. Ядра визуально не увеличены, с чёткими границами. Встречаются клетки в состоянии митоза.

В гистологической картине печени II опытной группы наблюдаются перипортальные клеточные пролифераты, преимущественно из клеток лимфоидного ряда. В отличии от I группы клеточная инфильтрация обнаруживается и интралобулярно. Наблюдается полнокровие всего сосудистого русла. Балочная структура долек сохранена, за исключение очагов расширения синусоидов в виде лакун, где наблюдается умеренная дискомплексациягепатоцитов (рис. 2В). Ядра не увеличены, границы их - чёткие.

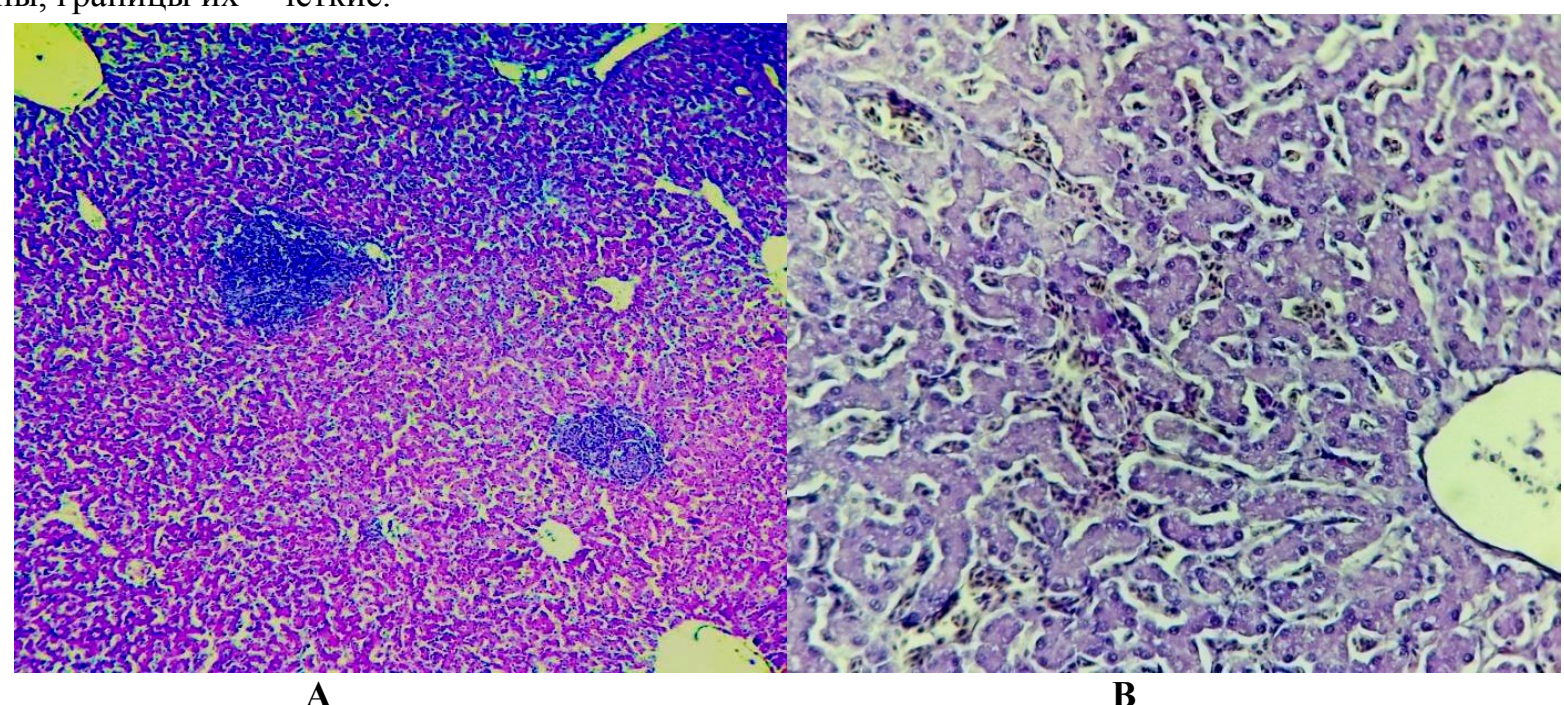

Рис. 2 - Микроструктура печени цыплят-бройлеров опытных групп, окраска и эоэином: А - I опытная группа (полнокровие печени и клеточные пролифераты в междольковой ткани), ув. 10×10; В - II опытная группа (полнокровие, мелкокапельная дистрофия гепатоцитов), ув. 400

Figure 2 - Microstructure of liver of broiler chickens of experimental groups, staining with hematoxylin and eosin: A - I experimental group (full blood of the liver and cell proliferation in the interlobular tissue), UV. 10×10; B - II experimental group (full blood, small-drop dystrophy of hepatocytes), UV. 400

Микроэлементный состав. Использование в рационе цыплят-бройлеров ультрадисперсного сплава (I группа) и органической формы (II группа) меди и цинка сопровождалось увеличением меди в организме цыплят-бройлеров на $51,63(\mathrm{P} \leq 0,01)$ и 13,22 \% в конце эксперимента соответственно. Цинк не имел достоверного увеличения и его концентрация в I группе на 1,4 \% превышала контроль, а во II группе была ниже контроля на 22,9 \% (рис. 3). 


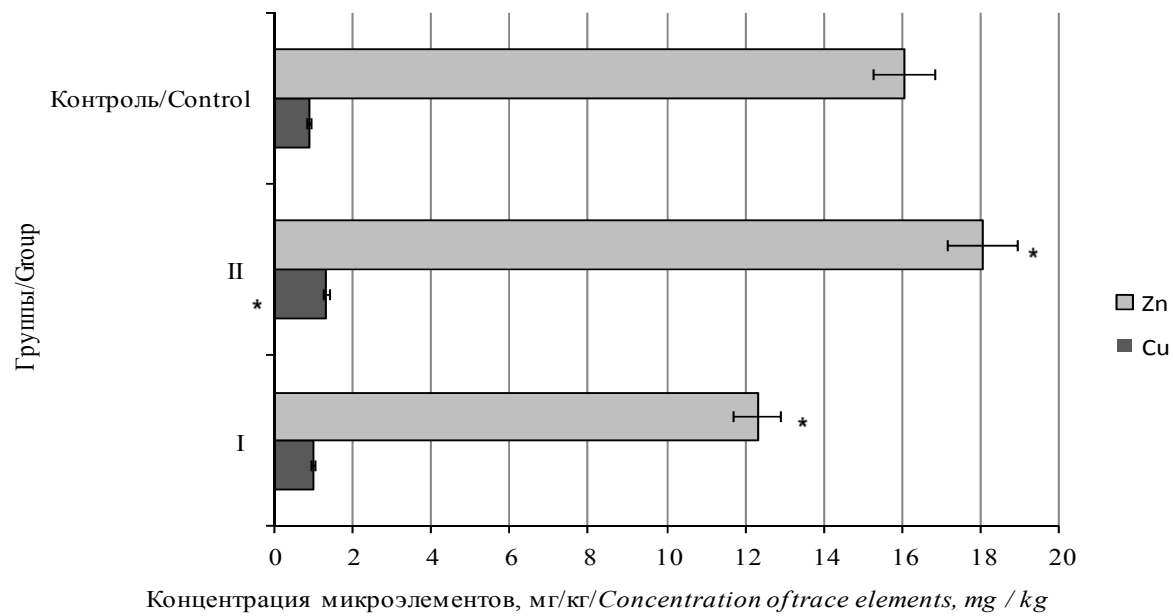

Рис. 3 - Концентрации меди (Cu) и цинка (Zn) в теле цыплят-бройлеров в конце эксперимента (средние значения \pm стандартная ошибка среднего, $\mathrm{M} \pm \mathrm{SEM})(\mathrm{n}=6)$

Figure 3 - Copper $(\mathrm{Cu})$ and zinc $(\mathrm{Zn})$ concentrations in broiler chickens during the experiment (mean values \pm standard error of the mean, $M \pm S E M)(n=6)$

В эксперименте, давая оценку концентрации меди и цинка в печени и пере, установлена зависимость накопления элемента от формы металла. Так, медь накапливается в ходе всего эксперимента в опытных группах по сравнению с контролем, с максимальной разницей $36,5 \%(\mathrm{P} \leq 0,05)$ в печени I группы к концу эксперимента (42 сутки) (табл. 2). Это отражается накоплением меди в пере на фоне потребления ультрадисперсного сплава меди и цинка (І группа) при разнице с контрольной группой в 2,5 раза $(\mathrm{P} \leq 0,01)$. Значения концентрации меди при введении её органической формы близки к контролю или превышают его.

Таблица 2. Концентрация меди и цинка в органах-мишенях: печени и пере цыплят-бройлеров в эксперименте (M $\pm S E M, n=6)$, мг/кг

Table 2. Concentration of copper and zinc in target organs: liver and feathers of broiler chickens in the experiment $(M \pm S E M, n=6)$

\begin{tabular}{|c|c|c|c|c|c|c|}
\hline \multirow{2}{*}{$\begin{array}{c}\text { Oрганы/ } \\
\text { Organs }\end{array}$} & \multicolumn{2}{|c|}{ I группа/I group } & \multicolumn{2}{|c|}{ II группа/II group } & \multicolumn{2}{|c|}{ контроль/control } \\
\hline & медь/copper & цинк/zinc & медь/copper & цинк/zinc & медь/copper & цинк/zinc \\
\hline \multicolumn{7}{|c|}{21 сутки/21 day } \\
\hline Печ & $1,40 \pm 0,14$ & $18,87 \pm 1,64$ & $1,75 \pm 0,30$ & $21,23 \pm 1,81$ & $1,19 \pm 0,06$ & $17,55 \pm 1,05$ \\
\hline Пе & $4,63 \pm 0,33$ & $150,5 \pm 11,36^{*}$ & $3,08 \pm 0,38$ & $114,33 \pm 4,5$ & $4,08 \pm 0,21$ & $100,35 \pm 7,55$ \\
\hline \multicolumn{7}{|c|}{28 сутки/ 28 day } \\
\hline Пе & $1,95 \pm 0,58$ & $12,93 \pm 0,80$ & $2,03 \pm 0,19$ & 1,26 & $1,77 \pm 0,14$ & $10,97 \pm 1,16$ \\
\hline Пepo/Feather & $2,34 \pm 0,22$ & $110,23 \pm 10,79$ & $3,46 \pm 0,13$ & $70,41 \pm 6,68$ & $2,15 \pm 0,17$ & $102,43 \pm 6,73$ \\
\hline \multicolumn{7}{|c|}{35 сутки/35 day } \\
\hline Печень/Liver & $1,64 \pm 0,04$ & $21,47 \pm 1,04$ & $1,92 \pm 0,07$ & $22,73 \pm 1,31$ & $1,77 \pm 0,14$ & $20,97 \pm 1,16$ \\
\hline Перо/Feather & $2,63 \pm 0,17$ & $107,17 \pm 10,58^{*}$ & $3,04 \pm 0,71$ & $78,22 \pm 2,13$ & $2,15 \pm 0,17$ & $72,43 \pm 6,73$ \\
\hline \multicolumn{7}{|c|}{42 сутки/42 day } \\
\hline Печень/Liver & $3,4 \pm 0,150 * *$ & $25,53 \pm 1,94 * *$ & $2,36 \pm 0,289$ & $22,23 \pm 1,49$ & $2,49 \pm 0,21$ & $15,33 \pm 1,10$ \\
\hline Перо/Feather & $5,02 \pm 0,247 * *$ & $62,97 \pm 2,24$ & $2,51 \pm 0,08$ & $60,87 \pm 5,42$ & $1,96 \pm 0,02$ & $54,33 \pm 4,04$ \\
\hline
\end{tabular}

Примечание: * - $\mathrm{P} \leq 0,05 ;$ ** $-\mathrm{P} \leq 0,01 /$ Note: * $-\mathrm{P} \leq 0.05$; ** $-\mathrm{P} \leq 0.01$ 
Концентрация цинка в печени цыплят-бройлеров в течение эксперимента изменяется волнообразно во всех группах (табл. 2). В конце первой недели эксперимента концентрация цинка в печени превосходит контрольные значения на 7,5 \% при скармливании органической формы (II группа). Накопление цинка в печени значимой разницы 66,8 \% $(\mathrm{P} \leq 0,01)$ достигает только к концу эксперимента (42 сутки) на фоне скармливания ультрадисперсного сплава (I группа).

Оценивая динамику уровня цинка в пере, хорошо заметна общая тенденция снижения его концентрации в течение эксперимента во всех группах. Концентрация цинка, близкая к значениям контрольной группы или незначительно её превосходящая, обнаружена в пере на фоне введения ультрадисперсного сплава (І группа).

\section{Обсуждение полученных результатов.}

Наши данные по стимуляции роста цыплят-бройлеров ультрадисперсными формами микроэлементов совпадают с выводами других исследователей, описывающих ростостимулирующие эффекты ультрадисперсных форм металлов, в том числе по сравнению с традиционными источниками микроэлементов (Mroczek-Sosnowska N et al., 2016; Scott A et al., 2018). При этом следует отметить, что достоверные отличия между группами по интенсивности роста в данном опыте получены на фоне быстрого роста подрощенной птицы. Сложно это объяснить только более высокой биодоступностью микроэлементов из ультрадисперсных источников. Возможно, это связанно с тем, что цыплята-бройлеры до начала основного экспериментального периода содержались на сбалансированном питании и накопили в организме значительный пул нутриентов, вполне достаточный для активного роста в последующем. Тем более, что необходимое количество микроэлементов поступало на протяжении всего эксперимента.

Возрастание продуктивности на фоне скармливания ультрадисперсного сплава, по нашему мнению, определялся иным механизмом действия ультрадисперсных форм на организм животного, описанным ранее (Yausheva E et al., 2015), в том числе через активизацию обмена аргинина и синтеза окиси азота. Подтверждением этой гипотезы являются данные, полученные в ходе предыдущих исследований, которые показали повышенную концентрацию NO-метаболитов в сыворотке крови цыплят на протяжении всего эксперимента (Яушева Е., 2016).

Направленность биохимических процессов в организме демонстрирует метаболическая ось: активность АСТ (цитолиз, реверсивный синтез глюкозы, активация митохондрий) - активность АЛТ (глюкозо-аланиновый цикл (ГАЦ) и аминирование пирувата) - активность ГГТ (транспорт аминокислот через мембраны) - уровень мочевины (интенсивность катаболизма и использование белков в глюконеогенезе через ГАЦ) (Фокина Е.Г. и Рослый И.М., 2013). Рассмотрим с этих позиций отдельно динамику каждого компонента метаболической оси.

Исходя из того, что фермент АСТ является как маркером цитолиза, так и показателем активности митохондрий в клетках организма (Sookoian S et al., 2015), можно предположить, что ультрадисперсная форма повышает скорость использования свободных аминокислот в синтезе энергии посредством цикла Кребса. Полученные данные, с одной стороны, свидетельствовали об изменении степени вовлечения аминокислотных остатков в биохимические процессы организма животных за счёт реакций переаминирования, а с другой - об изменении проницаемости клеточных мембран внутренних органов. Повышенная активность АЛТ указывает на изменение метаболических потоков в экспериментальных группах по сравнению с контрольной в большей степени для ультрадисперсной формы (Шамсутдинова И.Р., 2015). Таким образом, динамичность ферментов зависит от формы минеральной добавки, поступающей в организм животных.

Динамика активности ГГТ как маркера аминокислотного баланса организма в эксперименте имеет тенденцию к снижению в большей степени при введении ультрадисперсной формы, вследствие отсутствия использования соматического пула белков и снижения транспорта аминокислот через мембраны.

Применение ультрадисперсного сплава увеличивает активность СОД в самом начале опыта, со снижением - к концу эксперимента. Таким образом, СОД как элемент блокировки реакций сво- 
боднорадикального окисления и первичный антиоксидант не допускает создание новых активных форм кислорода, превращая супероксид в неактивную $\mathrm{H}_{2} \mathrm{O}_{2}$, в большей степени на фоне применения ультрадисперсного сплава, по сравнению со смесью аспарагинатов этих элементов. Некоторые элементы в форме наночастиц, например Nano-Se, играют защитную роль, предотвращая окислительный стресс (Shirsat S and Kadam A, 2016). Подобные результаты демонстрируют ряд исследований. Так, биологически активные наночастицы оксида цинка, меди, селена и железа улучшают показатели роста и антиоксидантную способность у бройлеров (Zhao CY et al., 2014; Joshua PP et al., 2016; Siddiqi K S et al., 2016). Состояние антиоксидантного статуса цыплят-бройлеров зависит от дозы введения. Так, можно повысить антиоксидантную и иммунную защиту цыплят, дополнив их рацион нано- $\mathrm{Cu}$ - до 12 мг на птицу в течение 6 недель кормления, то есть до уровня не более 7 \% по рекомендации NRC (National Research Council) по выращиванию цыплят-бройлеров (MroczekSosnowska $\mathrm{N}$ et al., 2016).

Общими морфологическими изменениями для печени цыплят-бройлеров всех групп являются полнокровие и полиморфноклеточная инфильтрация с тенденцией к развитию жировой дистрофии. Оценка накопления жировых капель в цитоплазме гепатоцитов неоднозначна (Wolford JH and Polin D, 1972). Это можно рассматривать как результат метаболических процессов, ведущих к повышенному синтезу жировых веществ - гепатозу (Трифонов Г.А. и др., 2009).

Отложение меди и цинка в организме при использовании ультрадисперсных, органических и неорганических источников было различным. Возможно, что биологическая доступность элементов из сплава была выше по сравнению с неорганическими и органическими формами. В свою очередь, из аспарагината биодоступность меди в сравнении с цинком оказалась выше. В этом случае антагонизм этих веществ мог привести к снижению усвояемости цинка. По этой причине использование методики раздельного скармливания меди и цинка оказывается успешной.

Этот факт можно объяснить конкуренцией на общие транспортёры для меди, цинка и других металлов II группы в кишечном тракте (Hind T et al., 2004). Благодаря своей высокой проникающей способности наночастицы металлов устремляются в клетки кишечника, минуя традиционные пути связывания и транспорта белками (Zhang H et al., 2015). В следствие этого транспортные системы, определяющие перенос цинка и меди в I опытной группе, могут быть использованы другими двухвалентными аналогами. Тогда как во II опытной группе, напротив, они используются по «назначению». Различный механизм приёма и использования металлов из различных форм в организме подопытной птицы находит доказательство динамикой концентраций этих компонентов в тканях и органах. Учитывая результаты исследований (Нестеров Д.В. и др., 2013), определяющих перо в качестве маркера элементной обеспеченности птицы, можно предположить, что элементный статус птицы на протяжении всего эксперимента непрерывно менялся. Причём приём ультрадисперсных форм микроэлементов определил более равномерное обеспечение медью организма птицы.

\section{Выводы.}

Таким образом, использованиеультрадисперсных форм меди и цинка в питании цыплятбройлеров сопровождается повышением биодоступности оцениваемых микроэлементов и продуктивным действием в сравнении с использованием неорганических и органических форм.

\section{Работа выполнена при финансовой поддержке РНФ проект № 20-16-00078}

\section{Литература}

1. Методические указания по оптимизации рецептов комбикормов для сельскохозяйственной птицы / В.И. Фисинин, И.А. Егоров, Т.Н. Ленкова, Т.М. Околелова, Г.В. Игнатова, А.Н. Шевяков, И.Г. Панин, В.В. Гречишников, П.А. Ветров, В.А. Афанасьев, Ю.А. Пономаренко. М.: ВНИТИП, 2009. 80 с. [Fisinin VI, Egorov IA, Lenkova TN, Okolelova TM, Ignatova GV, Shevyakov AN, Panin IG, Grechishnikov VV, Vetrov PA, Afanas'ev VA, Ponomarenko YuA. Metodicheskie ukazaniya 
po optimizatsii retseptov kombikormov dlya sel'skokhozyaistvennoi ptitsy. Moscow: VNITIP; 2009:80 p. (InRuss)].

2. Морфофункциональное состояние печени кур при включении в рацион селенопирана / Г.А. Трифонов, Н.Ю. Свиридова, К.А. Пресняков, К.А. Кулешов // Вестник Алтайского государственного аграрного университета. 2009. № 11(61). С. 59-62. [Trifonov GA, Sviridova NYu, Presnyakov KA, Kuleshov KA. Morfofunktsional'noe sostoyanie pecheni kur pri vklyuchenii v ratsion selenopirana. Vestnik Altaiskogo gosudarstvennogo agrarnogo universiteta. 2009;11(61):59-62. (In Russ)].

3. Наночастицы $\mathrm{Fe}$ в сочетании с аминокислотами изменяют продуктивные и иммунологические показатели у цыплят-бройлеров / Е.В. Яушева, С.А. Мирошников, Д.Б. Косян, Е.А. Сизова // Сельскохозяйственная биология. 2016. Т. 51. №6. С. 912-920. doi: 10.15389/agrobiology.2016.6.912rus [Yausheva EV, Miroshnikov SA, Kosyan DB, Sizova EA. Fe Nanoparticles in combination with amino acids change productive and immunological parameters in broiler chickens. Agricultural Biology. 2016;51(6):912-920. (In Russ)]. doi: 10.15389/agrobiology.2016.6.912eng

4. Способ оценки элементного статуса птицы по перу: пат. Рос. Федерация 2478956 / Д.В. Нестеров, С.А. Мирошников, О.Ю. Сипайлова, С.В. Лебедев, А.А. Бирюков, Е.А. Русакова, О.Н. Суханова, О.В. Кван, Ш.Г. Рахматуллин. Заявл. 24.10.11; опубл. 10.04.13; Бюл. № 10 [Nesterov DV, Miroshnikov SA, Sipaylova OYu, Lebedev SV, Biryukov AA, Rusakova EA, Sukhanova ON, Kvan OV, Rakhmatullin ShG. Sposob otsenki elementnogo statusa ptitsy po peru: pat. Ros. Federatsiya 2478956. Zayavl. 24.10.11; Opubl. 10.04.13; Byul. № 10 (In Russ)].

5. Сравнительные испытания ультрадисперсного сплава, солей и органических форм $\mathrm{Cu}$ и $\mathrm{Zn}$ как источников микроэлементов в кормлении цыплят-бройлеров / Е.А. Сизова, С.А. Мирошников, С.В. Лебедев, Ю.И. Левахин, И.А. Бабичев, В.И. Косилов // Сельскохозяйственная биология. 2018. T. 53. № 2. C. 393-403. doi 10.15389/agrobiology.2018.2.393rus [Sizova EA, Miroshnikov SA, Lebedev SV, Levakhin YuI, Babichev IA, Kosilov VI. Comparative tests of ultrafine alloy, salts and organic forms of $\mathrm{Cu}$ and $\mathrm{Zn}$ as sources of trace elements in feeding broiler. Agricultural biology. 2018;53(2):393-403. (In Russ)]. doi 10.15389/agrobiology.2018.2.393eng

6. Фокина Е.Г., Рослый И.М. Адаптивная ферментемия: монография. Saarbrucken: Lambert Academic Publishing, 2013. 110 c. [Fokina EG, Roslyi IM. Adaptivnaya fermentemiya: monografiya. Saarbrucken: Lambert Academic Publishing; 2013:110 p. (In Russ)].

7. Шамсутдинова И.Р. Влияние наночастиц серебра на некоторые функции печени в организме животных // Новая наука: теоретический и практический взгляд. 2015. Вып. 5-3. С. 22-25. [Shamsutdinova IR. The Influence of silver nanoparticles on some liver functions in animals. [Shamsutdinova IR. Vliyanie nanochastits serebra na nekotorye funktsii pecheni v organizme zhivotnykh. Novaya nauka: teoreticheskii i prakticheskii vzglyad. 2015;5-3:22-25. (In Russ)].

8. Farag MR, Alagawany M, AbdEl-Hack ME, Arif M, Ayasan T, Dhama K, PatraA, Karthik K. Role of chromiumin poultry nutrition and health: Beneficial applications and toxic effects. International Journal of Pharmacology. 2017;13(7): 907-915. doi: 10.3923/ijp.2017.907.915

9. Hajializadeh F, Ghahri H, Talebi A. Effects of supplemental chromium picolinate and chromium nanoparticles on performance and antibody titers of infectious bronchitis and avian influenza of broilerchickens under heat stress condition. Veterinary Research Forum. 2017;8(3):259-264.

10. Lind T, Lonnerdal B, Stenlund H, Gamayanti IL, Ismail D et al. A community-based randomized controlled trial of iron and zinc supplementation in Indonesian infants: effects on growth and development. The American Journal of clinical nutrition. 2004;80:729-736. doi: 10.1093/AJCN/80.3.729

11. Joshua PP, Valli C, Balakrishnan V. Effect of in ovo supplementation of nano forms of zinc, copper, and selenium on post-hatch performance of broilerchicken. Vet World. 2016;9(3):287-294. doi: 10.14202/vetworld.2016.287-294

12. Miroshnikova E, Arinzhanov A, Kilyakova Y, Sizova E, Miroshnikov S. Antagonist metal alloy nanoparticles of iron and cobalt: impact on trace element metabolism in carp and chicken. Human and Veterinary Medicine. International Journal of the Bioflux Society. 2015;7(4):253-259. 
13. Mishra B, Patel BB, Tiwari S. Colloidal nanocarriers: a review on formulation technology, types and applications toward targeted drug delivery. Nanomed-Nanotechnol. 2010; 6(1):9-24. doi: 10.1016/j.nano.2009.04.008

14. Mohammadi V, Ghazanfari S, Mohammadi-Sangcheshmeh A, Nazaran MH. Comparative effects of zinc-nano complexes, zinc-sulphate and zinc-methionine on performance in broilerchickens. British Poultry Science. 2015;56(4):486-493. doi: 10.1080/00071668.2015.1064093

15. Mroczek-Sosnowska N, Lukasiewicz M, Wnuk A, Sawosz E, Niemiec J, Skot A et al. In ovo administration of copper nanoparticles and copper sulfate positively influences chicken performance. Journal of the Science of Food and Agriculture 2016;96(9):3058-3062. doi: 10.1002/jsfa.7477

16. Ognik K, Sembratowicz I, Cholewińska E, Jankowski J, Kozlowski K, Juskiewicz J. The effect of administration of copper nanoparticles to chickens in their drinking water on the immune and antioxidant status of the blood. Animal Science Journal. 2018;89(3):579-588. doi: 10.1111/asj.12956

17. Scott A, Vadalasetty KP, Lukasiewicz M, Jaworski S, Wierzbicki M, Chwalibog A et al. Effect of different levels of copper nanoparticles and copper sulphate on performance, metabolism and blood biochemical profiles in broiler chicken. Journal of Animal Physiology and Animal Nutrition. 2018;102(1):364-373. doi: 10.1111/jpn.12754

18. Shirsat S, Kadam A, Mane RS, Jadhav VV, Zate MK, Naushad M et al. Protective role of biogenic selenium nanoparticles in immunological and oxidative stress generated by enrofloxacin in broiler chicken. Dalton Transactions. 2016;45(21):8845-8853. doi: 10.1039/C6DT00120C

19. Siddiqi KS, Ur Rahman A, Husen T, Husen A. Biogenic fabrication of iron/iron oxide nanoparticles and their application. Nanoscale research letters. 2016;11(1):498. doi: 10.1186/s11671-016-1714-0

20. Sookoian S, Pirola CJ. Liver enzymes, metabolomics and genome-wide association studies: from systems biology to the personalized medicine. Gastroenterol. 2015;21(3):711-725. doi: 10.3748/wjg.v21.i3.711

21. Yausheva E, Miroshnikov S, Sizova E, Miroshnikova E, Levahin V. Comparative assessment of effect of cooper nano and microparticles in chicken. Oriental Journal of Chemistry. 2015;31(4):23272336. doi: http://dx.doi.org/10.13005/ojc/310461

22. Zhang H, Ji Q, Huang C, Zhang S, Yuan B, Yang K, Ma YQ. Cooperative transmembrane penetration of nanoparticles. Sci Rep. 2015;27(5):10525. doi: 10.1038/srep10525

23. Zhang J, Spallholz J.Toxicity of selenium compounds and nano-selenium particles. In: Casciano D, Sahu SC, editors. Handbook of Systems Toxicology. West Sussex, UK: John Wiley and Sons; 2011:1-15. doi: 10.1002/9780470744307.GAT243

24. Zhao CY, Tan SX, Xiao XY, Qiu XS, Pan JQ, Tang ZX. Effects of dietary zinc oxide nanoparticles on growth performance and antioxidative status in broilers. Biol Trace Elem Res. 2014;160(3):361-367. doi: 10.1007/s12011-014-0052-2

\section{References}

1. Fisinin VI, Egorov IA, Lenkova TN, Okolelova TM, Ignatova GV, Shevyakov AN, Panin IG, Grechishnikov VV, Vetrov PA, Afanas'ev VA, Ponomarenko YuA. Methodical instructions on optimization of compound feed recipes for agricultural poultry. Moscow: VNITIP; 2009:80 p.

2. Trifonov GA, Sviridova NYu, Presnyakov KA, Kuleshov KA. Morphofunctional state of chicken liver when Selenopiranum is included in the diet. Bulletin of the Altai state agrarian University. 2009; 11(61):59-62.

3. Yausheva EV, Miroshnikov SA, Kosyan DB, Sizova EA. Fe Nanoparticles in combination with amino acids change productive and immunological parameters in broiler chickens. Agricultural Biology. 2016;51(6):912-920. doi: 10.15389/agrobiology.2016.6.912eng

4. Nesterov DV, Miroshnikov SA, Sipaylova OYu, Lebedev SV, Biryukov AA, Rusakova EA, Sukhanova ON, Kvan OV, Rakhmatullin ShG. Method for assessing the elemental status of a bird by feather: pat. Ros. Federatsiya 2478956. Declared 24.10.11; published 10.04.13; Byul. Byul. No 10. 
5. Sizova EA, Miroshnikov SA, Lebedev SV, Levakhin YuI, Babichev IA, Kosilov VI. Comparative tests of ultrafine alloy, salts and organic forms of $\mathrm{Cu}$ and $\mathrm{Zn}$ as sources of trace elements in feeding broiler. Agricultural Biology. 2018;53(2):393-403. doi 10.15389/agrobiology.2018.2.393eng

6. Fokina E.G., Roslyi I.M. Adaptive fermentemia: monograph. Saarbrucken: Lambert Academic Publishing; 2013:110 p.

7. Shamsutdinova IR. Shamsutdinova IR. The Influence of silver nanoparticles on some liver functions in animals. New science: a Theoretical and Practical view. 2015;5-3:22-25.

8. Farag MR, Alagawany M, AbdEl-Hack ME, Arif M, Ayasan T, Dhama K, PatraA, Karthik K. Role of chromiumin poultry nutrition and health: Beneficial applications and toxic effects. International Journal of Pharmacology. 2017;13(7): 907-915. doi: 10.3923/ijp.2017.907.915

9. Hajializadeh F, Ghahri H, Talebi A. Effects of supplemental chromium picolinate and chromium nanoparticles on performance and antibody titers of infectious bronchitis and avian influenza of broilerchickens under heat stress condition. Veterinary Research Forum. 2017;8(3):259-264

10. Lind T, Lonnerdal B, Stenlund H, Gamayanti IL, Ismail D et al. A community-based randomized controlled trial of iron and zinc supplementation in Indonesian infants: effects on growth and development. The American Journal of clinical nutrition. 2004;80:729-736. doi: 10.1093/AJCN/80.3.729

11. Joshua PP, Valli C, Balakrishnan V. Effect of in ovo supplementation of nano forms of zinc, copper, and selenium on post-hatch performance of broilerchicken. Vet World. 2016;9(3):287-294. doi: 10.14202/vetworld.2016.287-294

12. Miroshnikova E, Arinzhanov A, Kilyakova Y, Sizova E, Miroshnikov S. Antagonist metal alloy nanoparticles of iron and cobalt: impact on trace element metabolism in carp and chicken. Human and Veterinary Medicine. International Journal of the Bioflux Society. 2015;7(4):253-259.

13. Mishra B, Patel BB, Tiwari S. Colloidal nanocarriers: a review on formulation technology, types and applications toward targeted drug delivery. Nanomed-Nanotechnol. 2010; 6(1):9-24. doi: 10.1016/j.nano.2009.04.008

14. Mohammadi V, Ghazanfari S, Mohammadi-Sangcheshmeh A, Nazaran MH. Comparative effects of zinc-nano complexes, zinc-sulphate and zinc-methionine on performance in broilerchickens. British Poultry Science. 2015;56(4):486-493. doi: 10.1080/00071668.2015.1064093

15. Mroczek-Sosnowska N, Lukasiewicz M, Wnuk A, Sawosz E, Niemiec J, Skot A et al. In ovo administration of copper nanoparticles and copper sulfate positively influences chicken performance. Journal of the Science of Food and Agriculture 2016;96(9):3058-3062. doi: 10.1002/jsfa.7477

16. Ognik K, Sembratowicz I, Cholewińska E, Jankowski J, Kozlowski K, Juskiewicz J. The effect of administration of copper nanoparticles to chickens in their drinking water on the immune and antioxidant status of the blood. Animal Science Journal. 2018;89(3):579-588. doi: 10.1111/asj.12956

17. Scott A, Vadalasetty KP, Lukasiewicz M, Jaworski S, Wierzbicki M, Chwalibog A, et al. Effect of different levels of copper nanoparticles and copper sulphate on performance, metabolism and blood biochemical profiles in broiler chicken. Journal of Animal Physiology and Animal Nutrition. 2018;102(1):364-373. doi: 10.1111/jpn.12754

18. Shirsat S, Kadam A, Mane RS, Jadhav VV, Zate MK, Naushad M et al. Protective role of biogenic selenium nanoparticles in immunological and oxidative stress generated by enrofloxacin in broiler chicken. Dalton Transactions. 2016;45(21):8845-8853.doi: 10.1039/C6DT00120C

19. Siddiqi KS, Ur Rahman A, Husen T, Husen A. Biogenic fabrication of iron/iron oxide nanoparticles and their application. Nanoscale research letters. 2016;11(1):498. doi: 10.1186/s11671-016-1714-0

20. Sookoian S, Pirola CJ. Liver enzymes, metabolomics and genome-wide association studies: from systems biology to the personalized medicine. Gastroenterol. 2015;21(3):711-725. doi: 10.3748/wjg.v21.i3.711

21. Yausheva E, Miroshnikov S, Sizova E, Miroshnikova E, Levahin V. Comparative assessment of effect of cooper nano and microparticles in chicken. Oriental Journal of Chemistry. 2015;31(4):23272336. doi: http://dx.doi.org/10.13005/ojc/310461

22. Zhang H, Ji Q, Huang C, Zhang S, Yuan B, Yang K, Ma YQ. Cooperative transmembrane penetration of nanoparticles. Sci Rep. 2015;27(5):10525. doi: 10.1038/srep10525 
23. Zhang J, Spallholz J.Toxicity of selenium compounds and nano-selenium particles. In: Casciano D, Sahu SC, editors. Handbook of Systems Toxicology. West Sussex, UK: John Wiley and Sons; 2011:1-15. doi: 10.1002/9780470744307.GAT243

24. Zhao CY, Tan SX, Xiao XY, Qiu XS, Pan JQ, Tang ZX. Effects of dietary zinc oxide nanoparticles on growth performance and antioxidative status in broilers. Biol Trace Elem Res. 2014;160(3):361-367. doi: 10.1007/s12011-014-0052-2

Сизова Елена Анатольевна, доктор биологических наук, доцент, руководитель центра «Нанотехнологии в сельском хозяйстве», Федеральный научный центр биологических систем и агротехнологий Российской академии наук, 460000, г. Оренбург, ул. 9 Января, д. 29, тел.: 8-912344-99-07, e-mail: Sizova.L78@yandex.ru; профессор кафедры биологии и почвоведения, Оренбургский государственный университет, 460018, г. Оренбург, пр. Победы, 13

Нечитайло Ксения Сергеевна, аспирант 2 года обучения, Федеральный научный центр биологических систем и агротехнологий Российской академии наук», 460000, г. Оренбург, ул. 9 Января, д. 29

Иванищева Анастасия Павловна, аспирант 1 года обучения, лаборант-исследователь центра «Нанотехнологии в сельском хозяйстве», Федеральный научный центр биологических систем и агротехнологий Российской академии наук, 460000, г. Оренбург, ул. 9 Января д. 29, тел.: 8 987-843-58-22, e-mail: n79228964398@yandex.ua

Рябов Николай Иванович, доктор сельскохозяйственных наук, ведущий научный сотрудник отдела технологии мясного скотоводства и производства говядины, Федеральный научный центр биологических систем и агротехнологий Российской академии наук, 460000 , г. Оренбург, ул. 9 Января д. 29

Поступила в редакцию 10 августа 2020 г.; принята после решения редколлегии 14 сентября 2020 г.; опубликована 30 сентября 2020 г. / Received: 10 August 2020; Accepted: 14 September 2020;

Published: 30 September 2020 